\title{
Mediterranean Surface Geostrophic Circulation from Satellite Gravity and Altimetry Observations
}

\author{
Vigo, M.I., · Sempere, M.D., · Chao, B.F., · Trottini, M.
}

Received: date / Accepted: date

\begin{abstract}
We present a data-based approach to study the mean and the climatology of the Surface Geostrophic Currents (SGC) for the Mediterranean Sea, using satellite ocean surface altimetry observations for 22 years (1993-2014) in conjunction with the geoid solution derived from the space mission of GOCE (Gravity field and steady-state Ocean Circulation Explorer; Release 4). The resultant product is the Mediterranean SGC velocity field, that we denote by $\mathrm{SGC}_{G O C E-A l t}$, given in spatial resolution of $1 / 4^{\circ}$ and monthly time resolution. It exhibits smaller scales and lower dynamic intensities in comparison with open oceans, making the Mediterranean Sea a challenging test case for our satellite-based analysis. The mean $\mathrm{SGC}_{G O C E-A l t}$ is largely consistent with previous findings but with additional circulation features in time and space. We also compare our results with the SGC output from the regional hydrodynamic model of Mercator that assimilates satellite altimetry, satellite sea surface temperature, and in-situ observations. The prominent SGC features agree well not only on the large and subbasin scales but also in the widespread mesoscale dynamics. We find however comparatively lower intensities than the Mercator model in general, with differences that are on average around 7 $\mathrm{cm} / \mathrm{s}$, but might reach $13 \mathrm{~cm} / \mathrm{s}$ in some coastal areas.
\end{abstract}

Keywords Surface Geostrophic Circulation · Mean Dynamic Topography · Gravity field and steady-state

Vigo, M.I., and Sempere, M.

Dept. Applied Mathematics, University of Alicante, Spain.

E-mail: vigo@ua.es

Chao, B.F.

Institute of Earth Sciences, Academia Sinica, Taipei, Taiwan, ROC.

Trottini, M.

Dept. Mathematics, University of Alicante, Spain. ocean circulation explorer (GOCE) - Mediterranean Sea

\section{Introduction}

The Mediterranean Sea is a semi-enclosed basin strongly susceptive to global climatic changes (e.g., IPCC 2013, Durrieu et al. 2011) which have vital implications in regional environmental and ecosystem conditions. The Mediterranean Sea circulation has been largely studied in the literature from in-situ observations, satellite data, and model simulated data (see, for instance, Robinson et al. 1991, Roussenov et al. 1995, Robinson et al. 1999, Millot et al. 2005, Buongiorno Nardelli et al. 2006, Bouffard et al. 2008a and references therein). More recently Poulain et al. (2012) studied the surface geostrophic circulation of the entire Mediterranean Sea for the period 1992-2010 based on drifter observations and sea surface altimetry data. Poulain et al. (2013) reviewed selected studies of the Mediterranean circulation based on drifter observations and ancillary remote-sensing observations of satellite altimetry and high-frequency coastal radars. In particular, the satellite altimetry missions have enabled the accurate determination of the Mediterranean Sea Surface Height ( $\mathrm{SSH}$ ), revealing its complex circulation behaviour (see, e.g., Bouffard et al. 2011, Jebri et al. 2016, 2017) in both spatial distribution and temporal evolution while allowing detailed studies toward a better understanding of the Mediterranean dynamics.

Recent advances in the estimation of the ocean Mean Dynamic Topography (MDT) have led to significant improvement in accuracy on the surface geostrophic circulation (SGC) estimates. This owes to the contribution of the 21 st century space gravity missions to our know- 
ledge of the Earth's geoid, specially the Gravity field and steady-state Ocean Circulation Explorer (GOCE) mission that provided a geoid with spatial resolution typically finer than $100 \mathrm{~km}$. According to the horizontal geostrophic balance, the MDT leads to the SGC at the spatial and temporal resolutions under consideration. In Bingham et al. (2011), Knudsen et al. (2011) and Sánchez-Reales et al. (2012), the ability of GOCE geoid to improve the MDT and consequently ocean circulation have been proved. The usefulness of this method is illustrated, for example, in Sánchez-Reales et al. (2014) on the SGC variations at global scales, providing a monthly climatology of the global ocean at quarter degree longitude-latitude grid resolution and resolving spatial scales as short as $140 \mathrm{~km}$.

The complex general circulation in the Mediterranean Sea is composed of three major interacting spatial scales, namely the basin, subbasin, and mesoscale, making the determination of SGC by a geodetic approach a challenge. Woodworth et al. (2015) reviewed the measurements of the Mediterranean MDT proving that the geodetic approach is comparable with the independent ocean approach from in situ oceanographic measurements and ocean modeling, and it is important in validating existing global ocean circulation models thereby contributing to their improvements. Menna et al. (2013) used combined geoid models assimilating GOCE data, to estimate the Mediterranean MDT and its mean SGC with promising results.

In this work, we develop a dataset referred to as $\mathrm{SGC}_{\text {GOCE }-A l t}$ for Mediterranean SGC using 22 years (1993- 2014) of SSH data from satellite radar altimetry missions in conjunction with a geoid solution based on the fourth release of GOCE data (see Förste et al. 2011). From $\mathrm{SGC}_{G O C E-A l t}$ we study the mean SCG and the seasonal climatology of the Mediterranean for the 1993-2014 period in terms of the flow velocity. The results are put in the context of existing literature and compared with the Mercator model simulated SGC.

\section{Data and Methodology}

\subsection{Absolute Dynamic Topography}

The absolute dynamic topography (ADT) is the departure of the Sea Surface Height (SSH) from the timeaveraged geoid $\mathrm{N}$ :

$$
A D T(x, y, t)=S S H(x, y, t)-N(x, y),
$$

where $x$ denotes the longitude, $y$ the latitude and $t$ time.

The SSH is measured by altimetry missions, and we retrieve the dataset from the Sea Level Climate Change
Initiative (CCI) project (http://www.esa-sealevel-cci.org/products) as a monthly merged solution from several satellite altimeter measurements (Jason-1, Jason-2, TOPEX/POSEIDON, ENVISAT, ERS-1, ERS-2, and GFO) for the 22 years of the time span from 01/01/1993 to $12 / 31 / 2014$. The data are anomalies with respect to the global high resolution 17-years mean sea surface DTU10-MSS, given at 1/4 degree grid with all recommended geophysical and atmospheric corrections applied (Product version 1.1, see Ablain et al. 2015 for more details). We add back this mean sea surface to recover the true $\mathrm{SSH}$.

We adopt the EIGEN-6C3 geoid solution, a high resolution global combined gravity field model based on the 4th release of the GOCE Direct Approach (see Förste et al. 2011 for details) has been used. Andersen et al. (2015) demonstrated that the MDT DTU13MDT combined with DTU13MSS can be used to derive realistic geostrophic currents comparable to oceanographic derived MDT. The MDT at each location is expressed as the difference between the MSS and the geoid. Thus, we obtain the ADT by combining the SSH with DTU13MDT and DTU13MSS (available via ftp.space.dtu.dk/DTU13, see Andersen et al. 2015 for details) computed by the Danish National Space Center using two decades of multi-mission satellite altimetry from 9 different satellites (Jason-1, Jason-2, TOPEX/POSEIDON, GFO, ICESAT, ERS-1, ERS-2, ENVISAT and Cryosat-2).

\subsection{Estimation of Surface Geostrophic Currents (SGC)}

The SGC speed in terms of the zonal component (eastward), $u_{s}$, and the meridional component (northward), $v_{s}$, follows immediately from the geostrophic equation for the balance between the pressure gradient force and the Coriolis force:

$$
\begin{aligned}
& u_{s}(t)=-\frac{g}{f} \frac{\partial A D T}{\partial y} \\
& v_{s}(t)=\frac{g}{f} \frac{\partial A D T}{\partial x}
\end{aligned}
$$

where $g$ is the gravitational acceleration, and $f=2 \omega \sin \phi$ is the Coriolis frecuency, which depends on the latitude $\phi$ ( $\omega$ denotes the rate of rotation of the Earth).

\subsection{Simulated SGC from Mercator Model}

We shall compare our results against the synthesized data from Mercator Ocean Project (mercator-ocean.eu). We use the product PSY2V4R4, an output of The Mediterranean Sea Physics Reanalysis assimilating in situ 
temperature and salinity profiles, and satellite sea surface temperature and sea level altimetry according to a three-dimensional variational scheme (OceanVar) (for more details see Adani et al. 2011). One of the outputs is the simulated Surface Currents as monthly maps from $01 / 01 / 2007$ to $12 / 31 / 2013$ with a spatial resolution of $1 / 16^{\circ}$. To obtain the gestrophic component of the Mercator Surface Current we subtracted the Ekman component of the Surface Currents as obtained from GEKCO2 product. The Ekman component was computed by Joël Sudre at LEGOS (France) from remote-sensing altimeter and scatterometer data sets (see Sudre et al. 2013), and is distributed by the CERSAT as daily Ekman Surface Currents maps with a spatial resolution of $1 / 4^{\circ}$.

\section{Results and discussion}

In this section we present the Mean Mediterranean SGC and the monthly climatology and seasonal variations of Mediterranean SGC based on the $\mathrm{SGC}_{G O C E-A l t}$ analysis. These are used to derive the main features of Mediterranean surface circulation that we sketch in Figure 1.a. Direction of the mean vectors of the flow superimposed to their norm is shown in Figure 1.b. Notice that due to the seasonal nature and/or decadal variability of several of the features in Mediterranean circulation, some of these features cancel out in Figure 1.b but can be recovered using: the mean speed, that is presented as the norm of the monthly vectors in Figure 1.c; the mean Ionian SCG for different periods that captures its distinct states of circulation in Figure 2; and the seasonal SCG means for some of the subbasins that we present in Figures 5-8 and subsection 3.2. In the latter subsection, monthly climatology of the $\mathrm{SGC}_{G O C E-A l t}$ as anomalies with respect to the mean is also presented to capture the seasonal variability for some of the main features. A comparison of our results with the Mercator model SGC for the period 2007-2013 is presented in subsection 3.3.

\subsection{Mean Mediterranean SGC}

The mean $\mathrm{SGC}_{G O C E-A l t}$ in Figure 1.a. is in good agreement with the well-studied general pattern of the Mediterra-nean Sea Circulation (Robinson et al. 1991, Roussenov et al. 1995, Robinson et al. 1999, Millot et al. 2005, Poulain et al. 2012). The circulation is characterized by the Atlantic Water Jet with its instabilities, bifurcations, and multiple pathways, which travels from Gibraltar to the Levantine basin (see Robinson et al. 2001). The Atlantic water inflows through the Alboran Sea, meandering around the two Alboran Gyres (AG) (with mean speeds exceeding $25 \mathrm{~cm} / \mathrm{s}$, see Figure 1.c) subject to a strong seasonal variations. It then forms the Algerian Current (AC) with mean speed around 10$15 \mathrm{~cm} / \mathrm{s}$, considerably lower than the $30 \mathrm{~cm} / \mathrm{s}$ reported by Poulain et al. 2012. The mesoscale meanders and eddies off Algeria (as reported by Millot, 1985) move eastward to the Sardinia Channel, and from there two streams of Atlantic water enter the Eastern Mediterranean through the Sicily Strait: the Atlantic Tunisian Current (ATC), first reported by Béranger et al. 2004, running along the coast of Tunisia; and the AtlanticIonian Stream (AIS) flowing off the southern coast of Sicily. The latter has a branch northward that becomes the Mid-Ionian Jet (MIJ), and a second branch turns southeastward and merges with a Bifurcation of the ATC (BATC) close to Lampedusa island, depending on the year it could be just mainly BATC or mainly AIS (see Jebri et al, 2017). The MIJ is almost cancelled out in our 22 years mean due to the decadal variability of the Ionian basin. The ATC splits in two branches the BATC and a second branch that continues all along the coast flowing eastward to the south Levantine basin as a border current. At the Gulf of Sirte we also observe a large anticyclonic gyre, the Sidra Gyre (Jebri et al. 2016). As the continuation of the BATC/AIS in the Levantine Basin, going a little northward at around $\left(32^{\circ} \mathrm{N}, 25^{\circ} \mathrm{E}\right)$, water flows by the central Levantine basin as the Mid Mediterranean Jet (MMJ) (Poulain et al. 2012). The MMJ bifurcates southwest of Cyprus with one branch flowing cyclonically around Cyprus forming the Cilician Current (CC) and joining the Asian Minor Current (AMC) (mean speed around $12 \mathrm{~cm} / \mathrm{s}$ ). A second branch goes southeast of Cyprus forming the Rhodes Gyre (RG). This is the beginning of the Atlantic Water outflow pathway. Circulation in the Levantine basin is characterized by large meanders and anticyclonic eddies south of the MMJ as the MersaMatruh Eddies (MME) and the Ierapetra Gyre (IG) in winter time (identified with mean speeds that exceed 25 $\mathrm{cm} / \mathrm{s}$ and subject to strong seasonality), and cyclonic gyres in the northern basin as the RG, whose northern part merges with the AMC. Northwest of Cyprus we observed a quite stable anticyclonic eddy, that was previously reported to be cyclonic (Malanotte-Rizzoli et al. 1999). Circulation in the Aegean Sea is mainly cyclonic, the water flows into the Aegean Sea along the eastern coast with mean velocities around $5 \mathrm{~cm} / \mathrm{s}$ and out along its western coast with mean velocities increasing from 10 to $15 \mathrm{~cm} / \mathrm{s}$ north to south. Then water continues its way towards the Northern Ionian basin flowing northwest of Crete around Peloponnese, where emerges south of the peninsula a strong permanent anticyclonic feature, the Pelops Gyre (PG) (see, for instance, Robin- 
son et al. 1991, Korres et al. 2000a), and forms in the Northern Ionian basin an eastern boundary current going northward fed by waters flowing westward north and south of Crete. The Adriatic sea is characterized by a cyclonic circulation with two well defined gyres located in the south and the middle of the basin the South Adriatic Gyre (SAG) and the Middle Adriatic Gyre (MAG) while for the northern part the behavior seems more anticyclonic except for the summer months when a cyclonic eddy is apparent (see Figure 7). This Adriatic mean circulation is in agreement with previous studies (Artegiani et al., 1997, Poulain at al. 2001, Poulain et al. 2012), except for the anticyclonic circulation in the Northern Adriatic apparent from autumn to spring that to our knowledge has not been previously reported.

The mean $\mathrm{SGC}_{G O C E-A l t}$ in the Tyrrhenean Sea shows an overall cyclonic circulation with a northwestward current that forms a permanent gyre at the southwest of the basin. Other important features in the basin that are almost cancelled in the mean due to high seasonal variability (see Section 3.2) are: the cyclonic North Tyrrhenian Gyre (NTG) east of the Bonifacio Strait; an anticyclonic gyre that appears in autumn months southern to the NTG; close to the eastern coast (at approximately $40^{\circ} \mathrm{N}$ ) an anticyclone eddy that reverse to cyclonic in winter months; and a second anticyclonic feature in the southeastern part of the basin, north of Sicily.

In the North Western Mediterranean we observe two main currents, the Northern Current (NC) going southeastward along the Italian, French and Spanish coast (speed around $5 \mathrm{~cm} / \mathrm{s}$ ) with a branch going westward that recirculates from the Balearic Islands along the west of Corsica back to the gulf of Genoa (with mean speed ranging between $8-12 \mathrm{~cm} / \mathrm{s}$ ), this branch is known in the literature as the North Balearic Front (Robinson 2001, Millot 2005). In the center of this feature is apparent a permanent cyclonic gyre off the Gulf of Lions, referred as the Gulf of Lions Gyre (GLG). This circulation scheme is in good agreement with previous studies, except for a bifurcation of the westward branch of the NC that continues westward towards the Sardinia Chanel, that is reported in Poulain et al. 2012, but not captured by our approach.

As observed before, most of the mesoscale eddies are averaged out in forming the mean (Figure 1.b), as they are subject to a strong seasonal variation (see Section 3.2 ). In the case of the Ionian Sea, also more permanent features are hardly discernible since the circulation in this region is characterized by a decadal oscillation the cancels them out, as documented in the literature in association with the Eastern Mediterranean Tran- scend (EMT) and the Adriatic-Ionian Bimodal Oscillating System (BiOS) (See Borzelli et al. 2009; Gaĉić et al. 2010; Bessières et al. 2013, and references in there). The Ionian Sea circulation shows two distinct states with a circulation reversal in the northern part of the Sea from a cyclonic to an anticyclonic mode and vice versa, inducing in turn a reversal in the sea level trend of the basin (Vigo et al. 2005, Del Rio et al. 2009, Vigo et al. 2012). We have computed the mean Ionian SGC for three consecutive periods: from January 1993 to June 1997; from July 1997 to December 2005; and from January 2006 to December 2010 (cf. Poulain et al. 2012, Borzelli et al. 2009; Gaĉić et al. 2010) to describe longterm circulation in the Ionian basin. The resulting maps are shown in Figure 2. For the first and third periods we can observe a strong MIJ (more intense in the first period) flowing on the northern Ionian Sea producing an overall anticyclonic circulation, while the middle period highlights a very weak MIJ with an AIS jet that reaches its strongest values when owing towards the center of the Ionian basin and a cyclonic gyre that develops northward.

\subsection{Monthly climatology and seasonal variations of} Mediterranean SGC

Figures 3 and 4 show the monthly climatology of the $\mathrm{SGC}_{G O C E-A l t}$ as anomalies with respect to to the mean (Figure 1.b). They capture a clear seasonal variability for some of the main features in Mediterranean circulation. We observe a general strengthening of the cyclonic circulation in winter and of the anticyclonic circulation in summer and autumn. Velocities are lower in summer and early autumn (from June to October) and higher in winter and early spring (from November to March) going eastward in the the southern part and westward in northern part. Notice that being these anomalies, a vector in Figures 3 and 4 with opposite direction to the corresponding vector in Figure 1.a should not be interpreted as a change in the direction of the circulation but rather as a decrease in velocity. This seasonal changes could be partly driven by the high seasonality of the inflow of Atlantic water into the Mediterranean through the Strait of Gibraltar that has its maximum in September (Soto-Navarro et al. 2010).

In Figures 5-8 we show the seasonal means for some of the subbasins in order to better visualize its seasonal variations. Notice that these maps (unlike Figures 3 and 4 that represent anomalies) are computed as the mean of the months corresponding to each season for the whole period 1993-2014. Seasons have been defined as: Winter (December, January, February); Spring 
(March, April, and May); Summer (June, July, and August); and Autumn (September, October, and November). The seasonal mean for the Western Mediterranean Basin is shown in Figure 5. We can observe that in the north Western Mediterranean Basin the NC flows southward along the coast with a branch that emerges at the Balearic subbasin (North Balearic Front) surrounding the GLG, forming a stable cyclonic structure all through the year. The GLG narrows in winter and spring increasing the velocities observed in the northern part of the NC (around $8 \mathrm{~cm} / \mathrm{s}$ ) and in the North Balearic Front (around $12 \mathrm{~cm} / \mathrm{s}$ ). In the southern basin we observe very clearly the east AG with a cyclonic circulation from autumn to spring that reverses in summer. Intensities are maximum in winter and summer (exceeding the $30 \mathrm{~cm} / \mathrm{s}$ ), and much lower in spring and autumn. The west AG is also apparent showing a cyclonic circulation in winter and spring that reverses in summer and autumn. Here maximum intensities (exceeding the $35 \mathrm{~cm} / \mathrm{s}$ ) are in autumn and in spring when the Atlantic water that flows in merges with the NC.

The observation that the AG circulation is cyclonic in certain seasons of the year is apparently in disagreement with existing literature that reports the two AG appear intermittently but always anticyclonic (see e.g., Velez-Belch, et al. 2005 and Snaith 2003). This discrepancy might be partially explained by the fact that, as we estimate only the gesotrophic circulation, the past studies often referred to the total circulation and it is well known that the Alboran Sea upper layer circulation driven by wind stress and atmosphere pressure is largely ageostrophic (see Viudez, et al. 1998 and 1996). In any case, the observed seasonal reversal of the two AG should be interpreted with caution considering the high variability of the mesoscale phenomena and the inadequate in-situ observations in the region.

The AC, characterized by meanders emerging around several cyclonic and anticyclonic gyres, is also easily identifiable from Figure 5. Maximum velocities are observed along the African coast in winter (around $10 \mathrm{~cm} / \mathrm{s}$ ).

The seasonal mean SGC in the Tyrrhenian basin is shown in Figure 6. The southern subbasin is characterized by a branch of the AIS that flows cyclonically toward the north, but with meanders emerging around several anticyclonic gyres along the Italian coast, as the one located approximately $40^{\circ} \mathrm{N}$ (that reverses to cyclonic in winter months), and the one located the southeastern part of the basin, north of Sicily. The main feature in the northern subbasin is a dipole composed of cyclonic and anticyclonic circulations observed in the northwest: the anticyclonic NTG (east of the Bonifacio Strait); and the North Tyrrhenian Cyclonic Gyre southern to it (see Marullo et al. 1994). This dipole feature displays a strong seasonal dependence in size and position, being stronger in autumn. These results are in good agreement with the circulation reported by Rinaldi et al. (2010).

The seasonal mean for the Adriatic sea is shown in Figure 7. The Adriatic general circulation system is confirmed as a global cyclonic circulation, except in the northern Adriatic area where an anticyclonic meander going northeast direction towards Trieste is apparent in autumn, winter and spring (we could not find any reference to this anticyclonic meander in the existing literature). Note that in this same region a cyclonic gyre also emerge in summer months. A similar gyre has been also reported by Artegiani et al. (1997) and Poulain et al. (2001) but they observed it in different periods. As shown in Figure 7 in the central and southern parts of the basin the well known cyclonic MAG and SAG are present throughout the year. Both gyres broadens in spring and summer and narrows in autumn and winter increasing velocities. The western border current, flowing southward along the Italian coast, and the eastern (and much weaker) border current, flowing northward, are also observed as permanent features. In both cases higher mean velocities are observed in the central part of the Adriatic (in summer, close to $15 \mathrm{~cm} / \mathrm{s}$ for the western border current; and in autumn, reaching 12 $\mathrm{cm} / \mathrm{s}$ for the eastern side). These velocities are lower than (about half of) those reported by Poulain et al. (2001) based on drifters data.

In the Eastern Mediterranean Basin (see Figure 8) the main seasonal variation regards the MMJ and the IG. Both shift their position seasonally with higher velocities in the central part of the basin in autumn. This is when IG mean velocities exceeds $30 \mathrm{~cm} / \mathrm{s}$ and IG circulates clockwise remaining southern of the MMJ. For the rest of the year the IG circulates counterclockwise and remains northern of the MMJ. This seasonal reversal of the circulation has been unreported previously, where the IG is described as an anticyclonic non-steady gyre, that is usually generated in the summer and might last from several months to years (see e.g., Ioannou, et al. 2017). As for the AG, this apparent discrepancy can be partly explained by the strong ageostrophic component of the IG due to the Etesian winds (see e.g., Mkhinini, et al. 2014)

Standard deviation of the monthly $\mathrm{SGC}_{G O C E-A l t}$ speed is shown in Figure 9. Notice that the color scale is designed to resolve regional features rather than extreme values and saturates at $15 \mathrm{~cm} / \mathrm{s}$. As expected from the annual climatology (Figures 3 and 4), the surface current with Atlantic origin is characterized by higher variability in the inflows of Atlantic water to the east along the southern part of western and east- 
ern basins (with peaks above $20 \mathrm{~cm} / \mathrm{s}$, saturated dark red in Figure 5), and mitigates in its return along the northern part of both basins. Significant variability can also be observed in areas corresponding to well known mesoscale dynamics, which include: the AG (with standard deviation (std) of the monthly speed around 12 $\mathrm{cm} / \mathrm{s}$ ); the different gyres that form the AC (std around $10 \mathrm{~cm} / \mathrm{s}$ ); the NTG (with lower std around $5 \mathrm{~cm} / \mathrm{s}$ ); the $\mathrm{PG}$ (with std around $8 \mathrm{~cm} / \mathrm{s}$ ); the IG which is the most active and intense gyre in the whole basin (with std around $20 \mathrm{~cm} / \mathrm{s}$ ); the MME (std around $15 \mathrm{~cm} / \mathrm{s}$ ); and the SE (std around $12 \mathrm{~cm} / \mathrm{s}$ ).

\subsection{Comparison with Simulated Mercator Surface Geostrophic Currents}

In this section we compare our $\mathrm{SGC}_{G O C E-A l t}$ with the SGC from the hydrodynamic model Mercator that assimilates in-situ, SST and altimetry data (see Section 2.2), hereafter $\mathrm{SGC}_{\text {Mercator }}$. The comparison is restricted to the seven-years period of 2007-2013 because of the Mercator data availability. Note that, unlike Mercator, here we use an independent geoid based on GOCE satellite gravity data which leads to an independent MDT from the assimilated altimetric anomalies for the $\mathrm{SGC}_{G O C E-A l t}$.

Figure 10 shows the mean SGC speed from both data sets. The annual mean $\mathrm{SGC}_{\text {Mercator }}$ Climatology shows a similar pattern but with higher velocities than that from $\mathrm{SGC}_{G O C E-A l t}$, mainly for the Algerian Current, the North Current, and the Cilician and Asia Minor Currents. The correlation between the two maps is 0.46 , and statistically significant at the 0.05 level. The map of correlations (see Figure 11.a) shows correlations ranging from 0.5 to 0.7 all along the main path of the Atlantic Stream System. Considering the complex representation of the vector velocity fields (in the form of $u+i v$, where $u$ and $v$ are the zonal and meridional components), we can obtain the complex correlation coefficient as described by Kundu (1975) whose magnitude gives the overall measure of correlation and whose phase gives the average relative displacement or veering between the two vector fields. The complex correlation coefficient between the mean SGC speed from both data sets is 0.27 , and the mean angular offset of veering is $-6.9^{\circ}$. The maps of veering angle and complex correlation coefficient are represented in Figures 11.b and 11.c respectively, notice that the angular offset of veering is more significant the higher the correlation is. The mean speed is in good agreement quantitatively in the eastern basin, while in the north part of the Western basin mean velocities are lower in the $\mathrm{SGC}_{G O C E-A l t}$.
Figure 12 shows the amplitude and phase of the SGC annual cycle for both data sets. The maximum values in Figure 12.b reach $14 \mathrm{~cm} / \mathrm{s}$ (with an average value of $2.3 \mathrm{~cm} / \mathrm{s}$ ) while in Figure 12.a maximum values are around $7 \mathrm{~cm} / \mathrm{s}$ (in average $1.5 \mathrm{~cm} / \mathrm{s}$ ). Again the main differences are located in current systems near coastal areas. However, as shown in Figures 12.c and 12.d, we obtain very close values for the phase, for example, for the Northern Current that reaches its maximum in the late winter, in agreement with Mercator and previous studies (e.g., Birol et al. 2010). Three plausible explanations of comparatively lower amplitudes in our results are: (i) the lower precision in the satellite gravity data, since small-scale circulation details could have been removed in the filtering processes (Sánchez-Reales et al., 2016); (ii) the limitations of the filtering process for altimetry data products that do not take into account the variability of signal-to-noise ratio from one mission to another and seasonally. The latter has been shown by Morrow et al. (2017) where fine scale ocean dynamics for northwestern Mediterranean Sea is addressed based on along track data from Jason-2, SARAL/AltiKa and CryoSat-2; and (iii) barotropic dynamics due to wind effects are removed from the altimetric signal whereas a model could reproduce such a dynamics (see Bouffard et al., 2008b). In interpreting the discrepancies between our approach and Mercator model, it should be noted that the model that assimilates in-situ, SST and altimetry data inherits some of the problems discussed above, and has its own uncertainties and therefore it cannot be considered as undisputed base for any comparison. Further research is needed to address these issues.

\section{Conclusions}

In this work we provide a mean and a monthly climatology for the Mediterranean SGC using 22 years of satellite ocean altimetry data and the geoid determination from the GOCE mission (Release 4). We reproduce the general known patterns of the Mediterranean Sea Circulation at the basin scale and subbasin scale (Robinson et al. 1991, Roussenov et al. 1995, Robinson et al. 1999, Millot et al. 2005, Poulain et al. 2012), and also report new findings. For the Ionian basin, decadal variations of the circulation associated to well marked events such as the EMT (Roether et al., 2007) and the Adriatic-Ionian BiOS evidenced by Gacićc et al. (2010) are well reproduced. The estimated mean Ionian SGC for three consecutive periods illustrate how the mean $\mathrm{SGC}_{G O C E-A l t}$ circulation there reverses in mid-1997 from an overall anticyclonic to a cyclonic circulation, and in late 2010 reverse again back to cyclonic. Our approach overcomes the main limitations of existing approaches, those based 
solely on altimetry data in lack of independent geoid as a reference for the altimetry derived SSH maps, while approximations based on in-situ data are sparse and inhomogeneous in temporal and spatial coverages. Most seasonal SGC variations here reported are in agreement with several studies at subregional level (Artegiani et al. 1997, Poulain et al. 2001, Birol et al, 2010, Rinaldi et al. 2010), though for some currents we obtain weaker velocities than in-situ observations (as the AC reported by Poulain et al. 2012). Some of the subbasins and seasonal mesoscale features, as the seasonal reverse of the AG and the IG, have not been documented previously, this indeed evidences the potential of this new approach to the SGC. Although, as discussed in the previous section, the high variability of the mesoscale phenomena in these subbasins, their ageostrophic nature and the limited availability of in-situ observations suggest that the reported results should be interpret with caution.

In the comparison with the hydrodynamic Mercator model that assimilates in-situ and altimetry data, we obtain similar patterns and intensities for the main characteristics at basin and subbasin scales. However for finer scale dynamics and specially near-coastal, our approach reproduces similar patterns and seasonality but weaker intensities compared to Mercator. We suspect that one of the main contributors to these discrepancy would be the filtering techniques on satellite data to remove the geophysical and instrumental corrections, where both altimetry and gravity are affected, though in different ways. Morrow et al. (2017) provided new evidences that signal-to-noise ratio varies from one mission to another, and seasonally. Moreover, the filtering process of gravity data has removed small-scale features affecting the resolution of the geoid and hence the resolution of the approach presented here. Other possible contributions could be associated with barotropic dynamics due to wind effects that are removed from the altimetric signal, but a model could reproduce (see Bouffard et al., 2008b).

As such, our present approach is meant to represent an evaluation tool for studying ocean dynamics at basin and subbasin scales while further comparisons and improvements are to be anticipated.

\section{Acknowledgements}

We thank the two anonymous reviewers whose constructive comments/suggestions helped improve and clarify this manuscript. We acknowledge the support of all data providers: ESA CCI Sea Level Project for the Altimetry data, DTU SPACE from the Danish National Space Center for MDT and MSS products, the surface currents from the Mercator Ocean Project, and LEGOS and CERSAT for the Ekman Surface Currents. The work is supported by Taiwan MoST grant \#1052811-M-001-031. M. Dolores Sempere is supported by the PhD grant UAFPU2014-5884 from the University of Alicante.

\section{References}

1. Ablain, M., Cazenave, A., Larnicol, G., Balmaseda, M., Cipollini, P., Faugre, Y., Fernandes, M. J., Henry, O., Johannessen, J. A., Knudsen, P., Andersen, O., Legeais, J., Meyssignac, B., Picot, N., Roca, M., Rudenko, S., Scharffenberg, M. G., Stammer, D., Timms, G., and Benveniste, J.: Improved sea level record over the satellite altimetry era (1993 2010) from the Climate Change Initiative project, Ocean Sci.,11, 6782, https://doi.org/10.5194/os11-67-2015, 2015.

2. Adani, M., Dobricic, S., and Pinardi, N. (2011). Quality assessment of a 1985-2007 Mediterranean Sea reanalysis. Journal of Atmospheric and Oceanic Technology, 28(4), 569-589.

3. Andersen, O. B., Knudsen, P., and Stenseng, L. (2015). The DTU13 MSS (Mean Sea Surface) and MDT (Mean Dynamic Topography) from 20 Years of Satellite Altimetry. International Association of Geodesy Symposia (pp. 1-10). Springer. https://doi.org/10.1007/1345-2015-182

4. Artegiani, A., Paschini, E., Russo, A., Bregant, D., Raicich, F., Pinardi, N., (1997). The adriatic sea general circulation. Part ii: Baroclinic circulation structure. Journal of Physical Oceanography 27 (8), 15151532.

5. Bèranger, K., L. Mortier, G.-P. Gasparini, L. Gervasio, M. Astraldi, and M. Crèpon (2004), The dynamics of the Sicily Strait: A comprehensive study from observations and models, Deep Sea Research II, 51, 411440.

6. Bessières, L. and Rio, M. H. and Dufau, C. and Boone, C. and Pujol, M. I. (2013), Ocean state indicators from MyOcean altimeter products. Ocean Science,9,3, pp. 545560. https://doi.org/10.5194/os-9-545-2013.

7. Bingham RJ., Knudsen P., Andersen O., and Pail, R. (2011) An initial estimate of the North Atlantic steady-state geostrophic circulation from GOCE. Geophys Res Lett, 38:L01606. https://doi.org/10.1029/2010GL045633.

8. Birol, F., Cancet, M., Estournel, C. (2010) Aspects of the seasonal variability of the Northern Current (NW Mediterranean Sea) observed by altimetry. Journal of Marine Systems, 81, 297-311. https://doi.org/10.1016/j.jmarsys.2010.01.005.

9. Borzelli, G. L. E., M. Gacic, V. Cardin, and G. Civitarese (2009), Eastern Mediterranean Transient and reversal of the Ionian Sea circulation, Geophys. Res. Lett., 36, L15108, doi:10.1029/2009GL039261.

10. Bouffard, J., S. Vignudelli, P. Cipollini, and Y. Menard (2008), Exploiting the potential of an improved multimission altimetric data set over the coastal ocean, Geophys. Res. Lett., 35, L10601, doi:10.1029/2008GL033488.

11. Bouffard, J., S. Vignudelli, M. Herrmann, F. Lyard, P. Marsaleix, Y. Mnard, and P. Cipollini, (2008) Comparison of ocean dynamics with a regional circulation model and improved altimetry in the North-western Mediterranean. Terr. Atmos. Ocean. Sci., 19, 117-133, doi: 10.3319/TAO.2008.19.1-2.117(SA) 
12. Bouffard, J., L. Roblou, F. Birol, A. Pascual, L. FeneglioMarc, M. Cancet, R. Morrow, and Y. Menard (2011), Introduction and assessment of improved coastal altimetry strategies: Case study over the North Western Mediterranean Sea, in Coastal Altimetry, edited by S. Vignudelli et al., Springer, Berlin.

13. Buongiorno Nardelli, B., O. Cavalieri, M.-H. Rio, and R. Santoleri (2006), Subsurface geostrophic velocities inference from altimeter data: Application to the Sicily Channel (Mediterranean Sea), J. Geophys. Res., 111, C04007, doi:10.1029/2005JC003191

14. Del Rio Vera, J., Criado-Aldeanueva, F., Lafuente, J., Soto-Navarro, J. (2009). A new insight on the decreasing sea level trend over the Ionian basin in the last decades. Global and Planetary Change. 68. 232-235. 10.1016/j.gloplacha.2009.04.002.

15. Durrieu de Madron, X. et al. (2011), Marine ecosystems responses to climatic and anthropogenic forcings in the Mediterranean. Progress in Oceanography, Volume 91, 97-166. https://doi.org/10.1016/j.pocean.2011.02.003

16. Förste C, Bruinsma S, Shako R, Marty J-C, Flechtner F, Abrikosov O, Dahle C, Lemoine J.-M, Neumayer KH, Biancale R, Barthelmes F, Knig R, Balmino G (2011) EIGEN-6 a new combined global gravity field model including GOCE data from the collaboration of GFZ-Potsdam and GRGS-Toulouse. Geophys Res Abstr 13:EGU2011-3242-2, EGU General Assembly

17. Gaĉić, M., G. L. Eusebi Borzelli, G. Civitarese, V. Cardin, and S. Yari (2010), Can internal processes sustain reversals of the ocean upper circulation? The Ionian Sea example, Geophysical Research Letters, 37(L09608).

18. Ioannou, A., Stegner, A., Le Vu, B.,Taupier-Letage, I., and Speich, S. (2017). Dynamical evolution of intense Ierapetra eddies on a 22 year long period. Journal of Geophysical Research: Oceans, 122, 92769298, doi:10.1002/2017JC013158

19. IPCC, 5th Assessment report (2013), Climate Change 2013: The Physical Science Basis. Contribution of Working Group I to the Fifth Assessment Report of the Intergovernmental Panel on Climate Change, edited by T. F. Stocker, D. Qin, G.-K. Plattner, M. Tignor, S. K. Allen, J. Boschung, A. Nauels, Y. Xia, V. Bex, and P. M. Midgley, Cambridge Univ. Press, Cambridge, U. K., New York, USA.

20. Jebri, F., F. Birol, B. Zakardjian, J. Bouffard, and C. Sammari (2016), Exploiting coastal altimetry to improve the surface circulation scheme over the central Mediterranean Sea, J. Geophys. Res. Oceans, 121, 4888-4909, doi:10.1002/2016JC011961

21. Jebri, F., Zakardjian, B., Birol, F., Bouffard, J., Jullion, L., and Sammari, C. (2017). Interannual variations of surface currents and transports in the Sicily Channel derived from coastal altimetry. Journal of Geophysical Research: Oceans, 122, doi:10.1002/2017JC012836

22. Knudsen P, Bingham R, Andersen O, Rio Marie-Helene (2011) A global mean dynamic topography and ocean circulation estimation using a preliminary GOCE gravity model. J Geodesy. https://doi.org/10.1007/s00190-0110485-8

23. Korres, G., Pinardi, N., Lascaratos, A.: The ocean response to low frequency interannual atmospheric variability in the Mediterranean Sea, Part I: Sensitivity experiments and energy analysis, J. of Climate, 13, 705731, 2000.

24. Kundu P.J. (1975) Ekman Veering Observed near the Ocean Bottom, J.Physical Oceanoghrapy, 6, 238-242.
25. Malanotte-Rizzoli P, Manca BB, Ribera d Acala M et al.(1999) The Eastern Mediterranean in the 80s and in the 90s: The big transition in the intermediate and deep circulations. Dyn. Atmos. Oceans 29: 365-395.

26. Marullo S., Santoleri R., and Bignami F., 1994. The surface characteristics of the Tyrrhenian sea : historical satellite data analysis. . In: La Violette, P. E.(Ed), Seasonal and interannual variability of the Western Mediterranean sea, Coastal and Estuarine Studies, 46, 135-154.

27. Menna, M., Poulain, P.M., Mauri, E., Sampietro, D., Panzetta, F., Reguzzoni, M. and Sanso, F. (2013) Mean surface geostrophic circulation of the Mediterranean Sea estimated from GOCE geoid models and altimetric mean sea surface: initial validation and accuracy assessment. Bollettino di Geofisica Teorica e Applicata, 54, 347365.https://doi.org/10.4430/bgta0104.

28. Millot, C. (1985) Some features of the Algerian Current J.Geophys. Res. 90(C4):7169-7176.

29. Millot, C. and Taupier-Letage, I. (2005) Circulation in the Mediterranean Sea. In: A. Saliot (ed.) The Handbook of Environmental Chemistry book series (volume 5K), pp. 29-66. Springer-Verlag, Heidelberg. https://doi.org/10.1007/b107143.

30. Mkhinini, N., A. L. S. Coimbra, A. Stegner, T. Arsouze, I. Taupier-Letage, and K. Béranger (2014), Long-lived mesoscale eddies in the eastern Mediterranean Sea: Analysis of 20 years of AVISO geostrophic velocities, J. Geophys. Res. Oceans, 119, 86038626, doi:10.1002/2014JC010176.

31. Morrow R., Carret A.,Birol F., Nino F., Valladeau G., Boy F., Bachelier C., and Zakardjian B. (2017) Observability of fine-scale ocean dynamics in the northwestern Mediterranean Sea. Ocean Sci., 13, 1329, 2017

32. Poulain P.-M.,2001: Adriatic Sea surface circulation as derived from drifter data between 1990 and 1999. J. Mar. Syst., 29, 332.

33. Poulain P.-M., Menna M. and Mauri E. (2012). Surface geostrophic circulation of the Mediterranean Sea derived from drifter and satellite altimeter data. J . Phys. Oceanogr., 42, 973-990.

34. Poulain, P.-M., A. Bussani, R. Gerin, R. Jungwirth, E. Mauri, M. Menna, and G. Notarstefano. 2013. Mediterranean surface currents measured with drifters: From basin to subinertial scales. Oceanography 26(1):3847, http://dx.doi.org/10.5670/oceanog.2013.03.

35. Rinaldi, E., B. Buongiorno Nardelli, E. Zambianchi, R. Santoleri, and P.?M. Poulain (2010), Lagrangian and Eulerian observations of the surface circulation in the Tyrrhenian Sea, J. Geophys. Res., 115, C04024, doi:10.1029/2009JC005535.

36. Robinson, A. R., Golnaraghi, M., Leslie, W. G., Artegiani, A., Hecht, A., Lazzoni, E., et al. (1991). The eastern Mediterranean general circulation: features, structure and variability. Dynamics of Atmospheres and Oceans, 15,215240

37. Robinson, A. R., Sellschopp, J., Warn-Varnas, A., Leslie, W. G., Lozano, C. J., Haley, P. J. Jr.,, et al. (1999). The Atlantic Ionian Stream. Journal of Marine Systems, 20, 129156.

38. Robinson, A.R., Leslie, W. G., Theocharis, A. and Lascaratos, A. (2001) Mediterranean Sea Circulation. Academic Press. https://doi.org/10.1006/rwos.2001.0376.

39. Roether, W., B. Klein, B. Manca, A. Theocharis, and A. Kioroglou (2007), Transient Eastern Mediterranean deep waters in response to the massive dense-water output of the Aegean Sea in the 1990s, Progress in Oceanography, 74,540571 . 
40. Roussenov, V., Stanev, E., Artale, V. and Pinardi, N. (1995) A seasonal model of the Mediterranean Sea general circulation. Journal of Geophysical Research, 100 (C7), 13515-13538. https://doi.org/95JC00233.01480227/95/95JC-00233\$05.00.

41. Sánchez-Reales, J.M., Vigo, M.I., Jin, S. G., and Chao, B. F. (2012), Global Surface Geostrophic Currents from Satellite altimetry and GOCE geoid. Marine Geodesy. 35:sup1, 175-189.

42. Sánchez-Reales, J.M., Vigo, M.I. and Trottini, M. (2014) Ocean Surface Geostrophic Circualtion Climatology and Annual Variations Inferred from Satellite Altimetry and GOCE Gravity Data. Pure Appl. Geophys. doi:10.1007/s00024-014-0981-x.

43. Sánchez-Reales, J.M., Andersen, O.B. and Vigo, M.I. (2016) Improving Surface Geostrophic Current from a GOCE-Derived Mean Dynamic Topography Using EdgeEnhancing Diffusion Filtering. Pure Appl. Geophys. doi:10.1007/s00024-015-1050-9

44. Snaith, H.M., Allen, J., Alderson, S., Guymer, T. (2003) Monitoring of the eastern alboran gyre using combined altimetry and in situ data. Philosophical Transactions of the Royal Society London A 361, 6570.

45. Soto-Navarro, J., F. Criado-Aldeanueva, J. GarcíaLafuente, and A. Sánchez-Román (2010), Estimation of the Atlantic inflow through the Strait of Gibraltar from climatological and in situ data, J. Geophys. Res., 115, C10023, doi:10.1029/2010JC006302.

46. Sudre, J., Maes, C., and Garcon, V. (2016) On the global estimates of geostrophic and Ekman surface currents. Limnology and Oceanography: Fluids and Environments, 3: 120. doi:10.1215/21573689-2071927

47. Vélez-Belch, P., Vargas-Yez, M., Tintor, J. (2005) Observation of a western alborn gyre migration event. Progress in Oceanography $66(24), 190210$.

48. Vigo, I., García, D., Chao, B.F. (2005) Change of sea level trend in the Mediterranean and Black seas. J. Mar. Res. 63, 10851100.

49. Vigo, M.I., Sánchez-Reales, J.M., Trottini M. and Chao B.F. (2011) Mediterranean Sea level variations: Analysis of the satellite altimetric data, 19922008. J. Geodyn. doi:10.1016/j.jog.2011.02.002

50. Viúdez, A., R. L. Haney, and J. Tintoré, (1996): Circulation in the Alboran Sea as determined by quasisynoptic hydrographic observations.Part II: Mesoscale ageostrophic motion diagnosed through density dynamical assimilation. J. Phys. Oceanogr., 26, 706724.

51. Viúdez, A., J. M. Pinot, and R. L. Haney (1998), On the upper layer circulation in the Alborn Sea, J. Geophys. Res., 103(C10), 21,65321,666,doi:10.1029/98JC01082.

52. Woodworth, P.L., Gravelle, M., Marcos, M. and Wöppelmann, G. (2015) The status of measurement of the Mediterranean mean dynamic topography by geodetic techniques. J. Geod., 89, 811-827. doi:10.1007/s00190015-0817-1. 


\section{a) Gestrophic surface circulation in Mediterranean Sea}

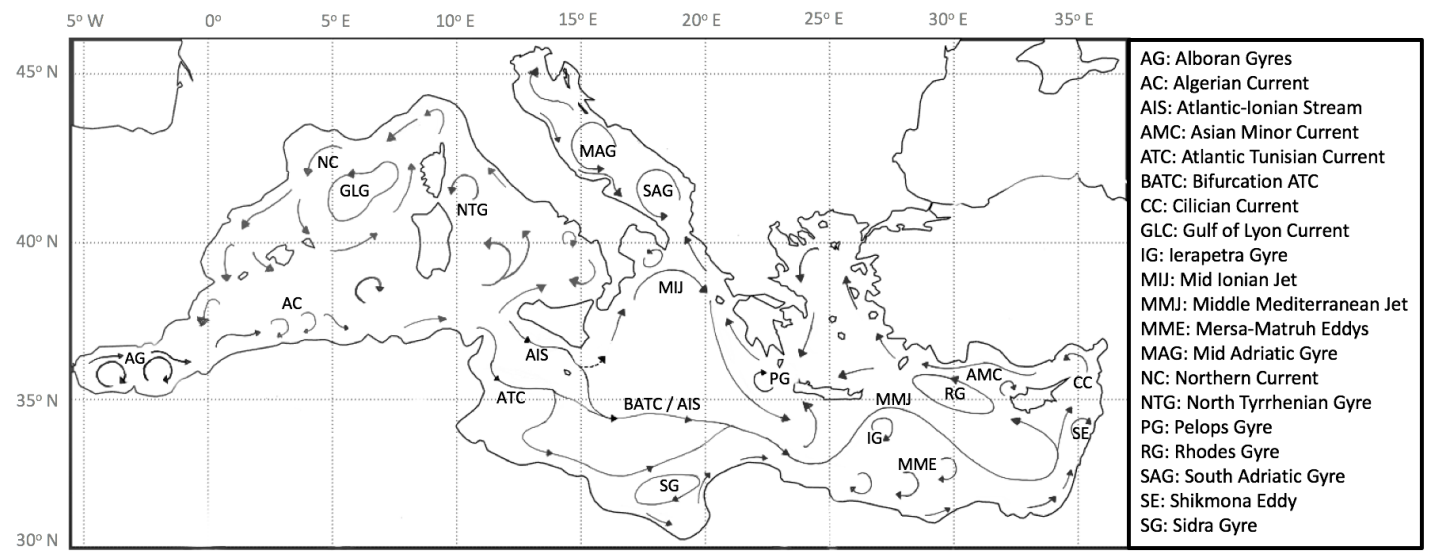

b) 1993-2014 Mean SGC

c) 1993-2014 Mean SGC Speed
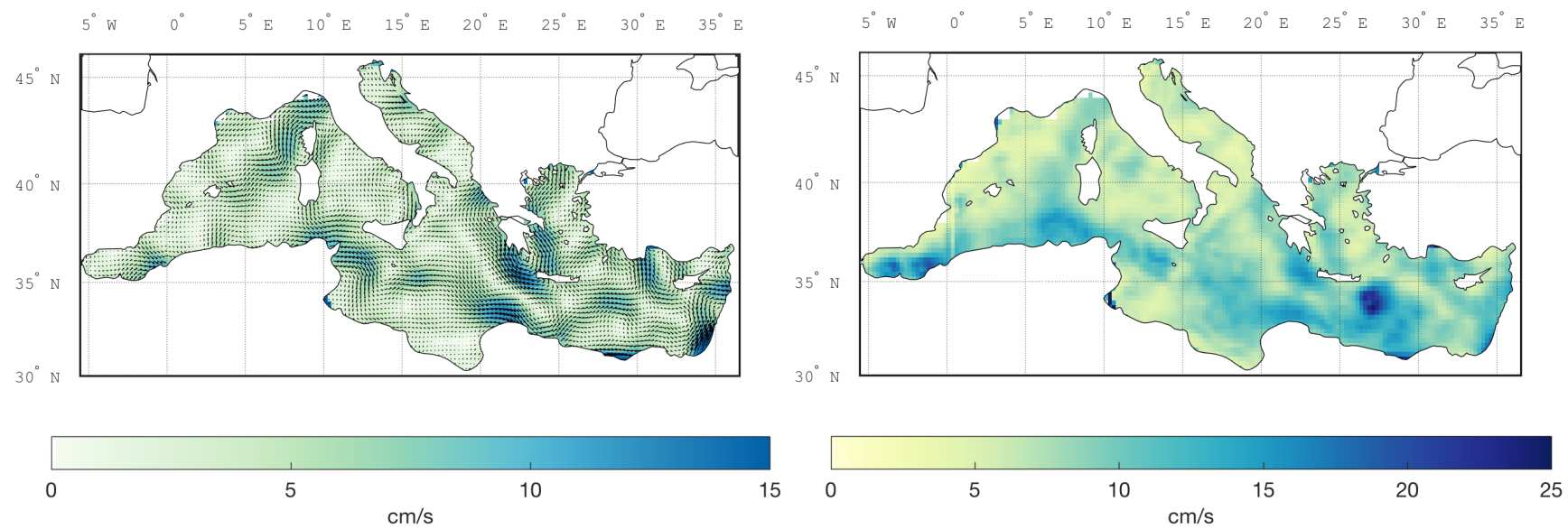

Fig. 1 1993-2004 Mean Mediterranean Surface Geostrophic Currents as estimated from satellite gravity and altimetry data. a) Main circulation features in the Mediterranean Sea according to $\mathrm{SGC}_{G O C E-A l t}$. b) Direction of mean flow vectors, and the color represents their norms; c) Mean of monthly $\mathrm{SGC}_{G O C E-A l t}$ speed.
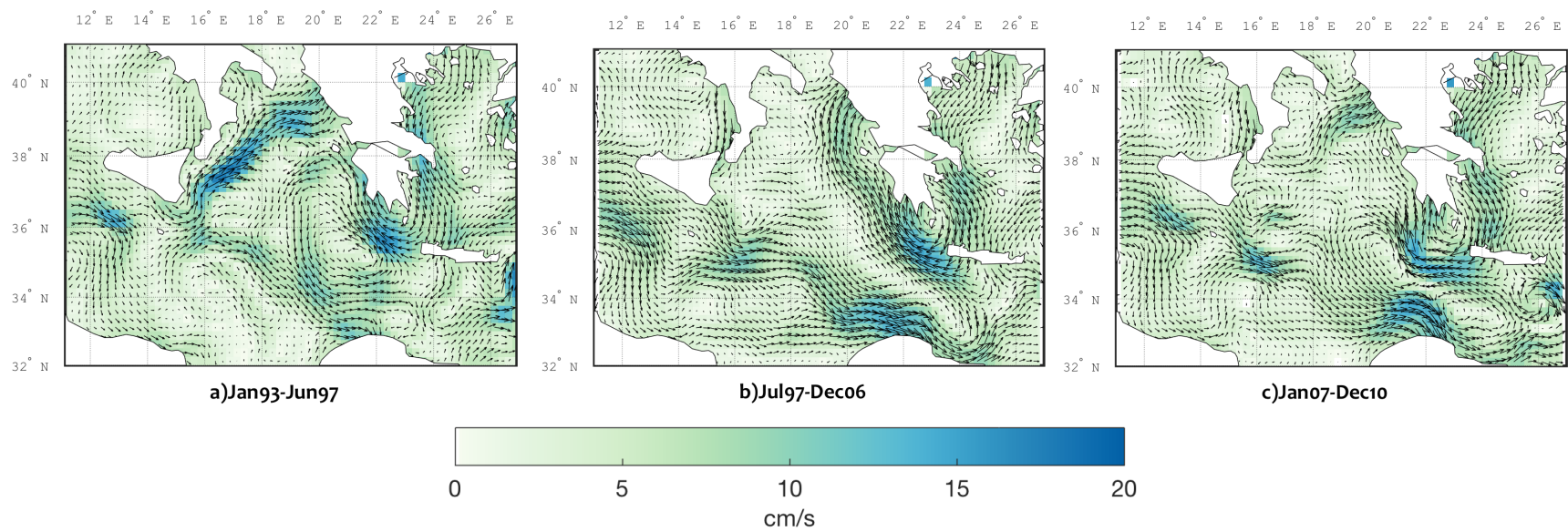

Fig. 2 Mean Ionian Surface Geostrophic Currents as estimated from satellite gravity and altimetry data for three different periods: a) from January 1993 to June 1997; b) from July 1997 to December 2005; and c) from January 2006 to December 2010. 


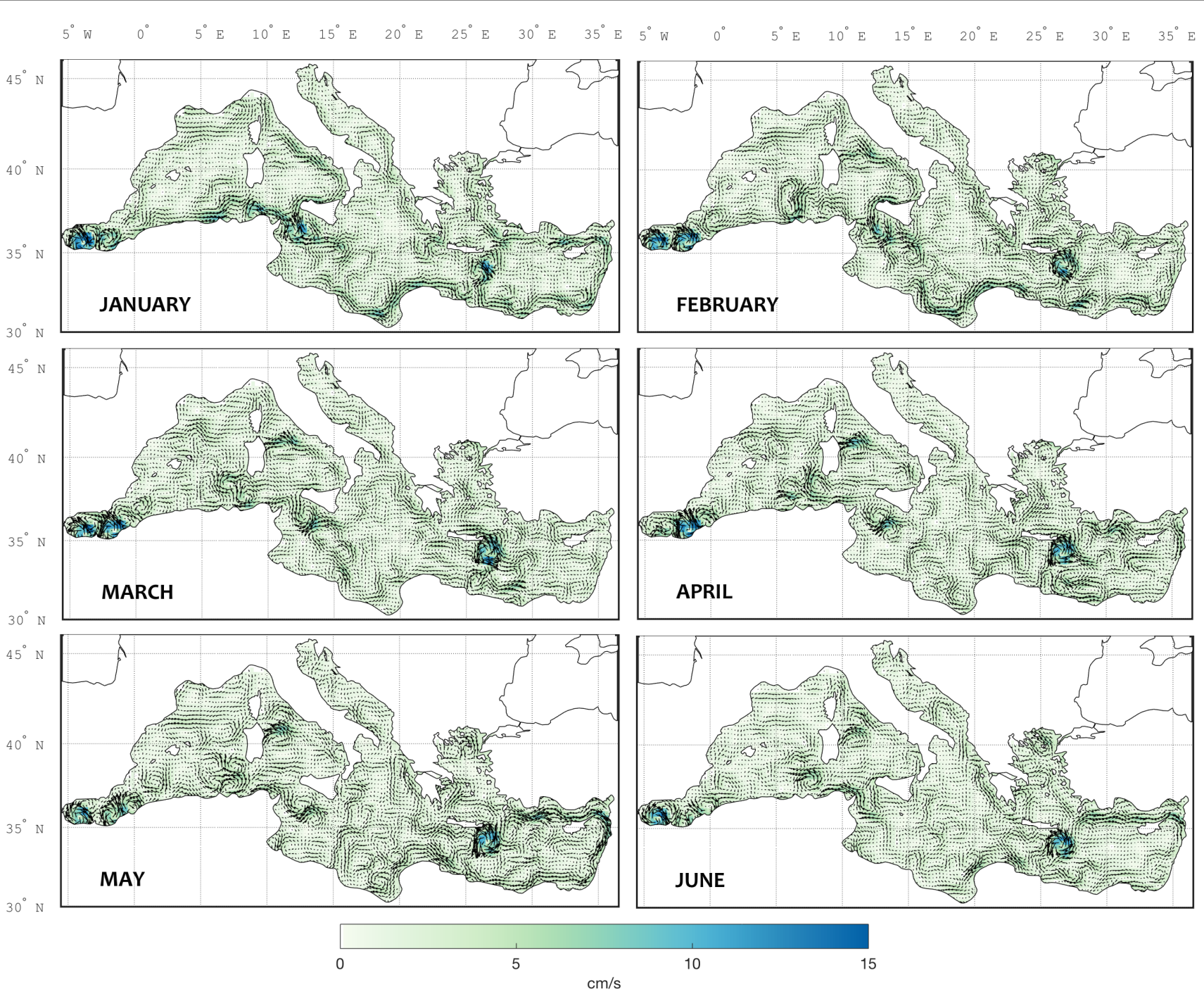

Fig. 3 Monthly climatology of the Mediterranean Surface Geostrophic Currents anomalies with respect to the 1993-2014 mean, shown in Figure 1a. Months from January to June, the month is indicated at the left bottom of each panel. 

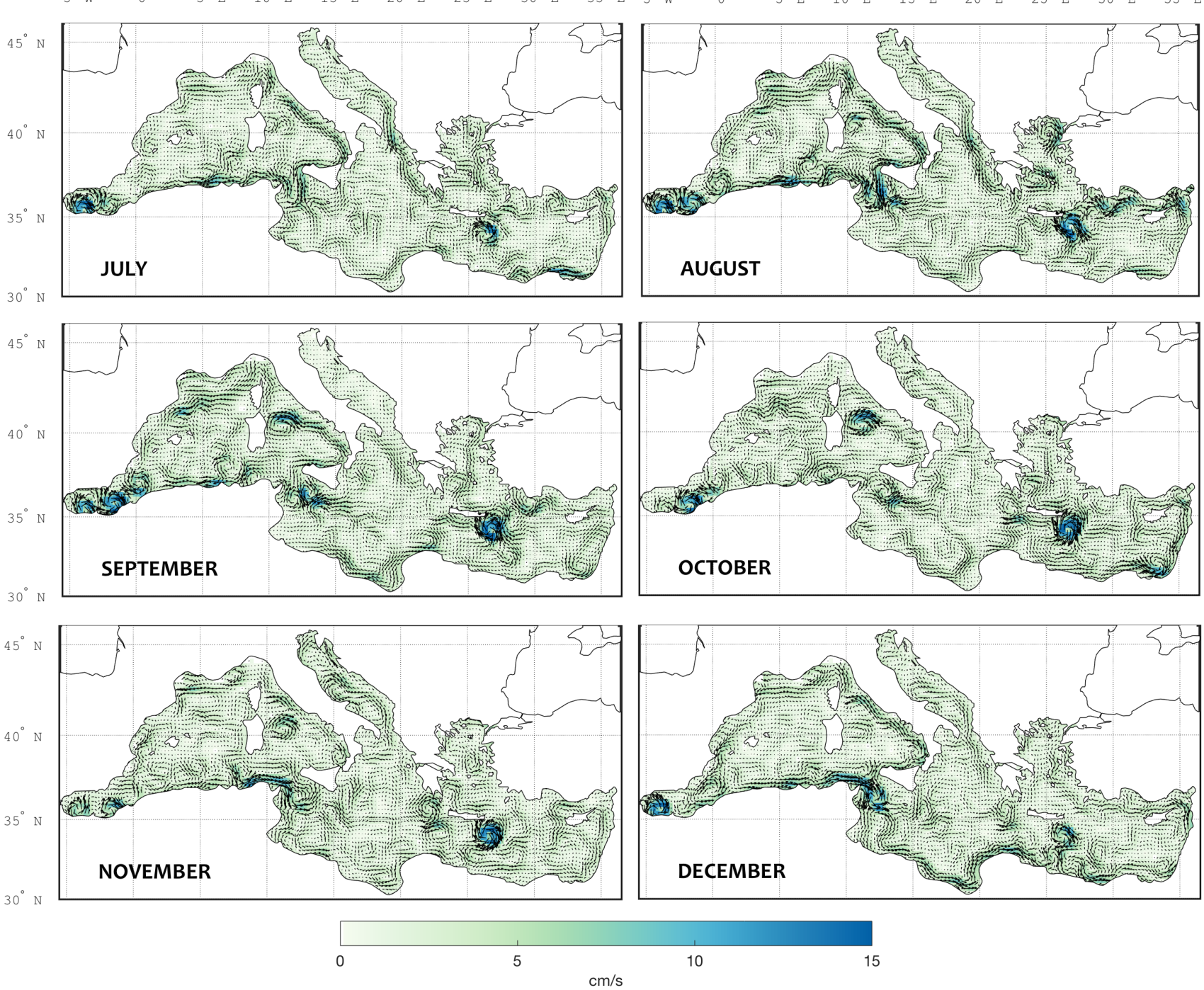

Fig. 4 Monthly climatology of the Mediterranean Surface Geostrophic Currents anomalies with respect to the 1993-2014 mean, shown in Figure 1a. Months from July to December, the month is indicated at the left bottom of each panel. 

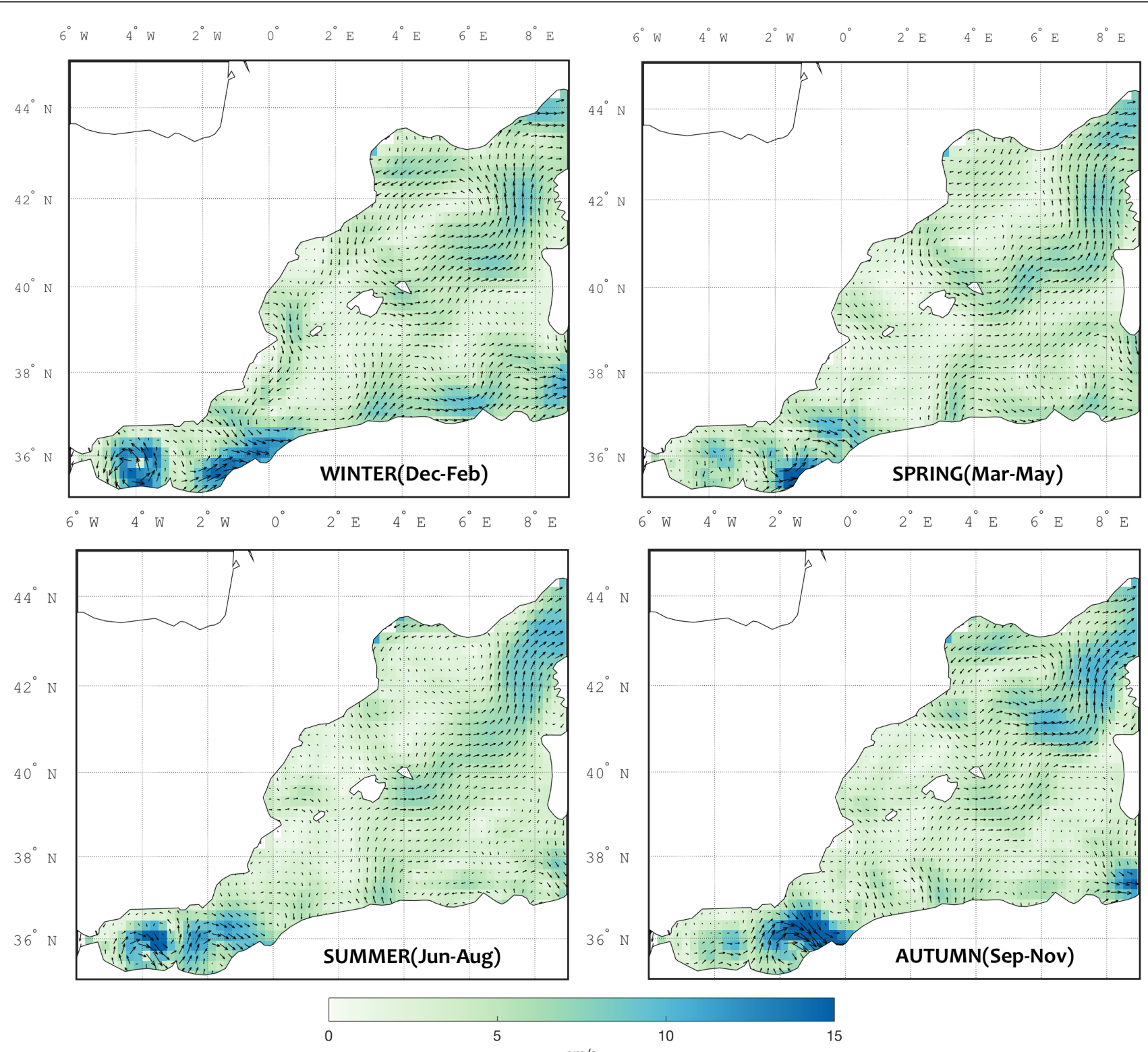

$\mathrm{cm} / \mathrm{s}$

Fig. 5 1993-2014 Seasonal Mean Western Mediterranean Surface Geostrophic Currents as estimated from satellite gravity and altimetry. Season (and corresponding months) is indicated at the right top of each panel. The color scale is designed to better visualize the full range of values and its saturated to $15 \mathrm{~cm} / \mathrm{s}$, though speed reaches up to $35 \mathrm{~cm} / \mathrm{s}$. 


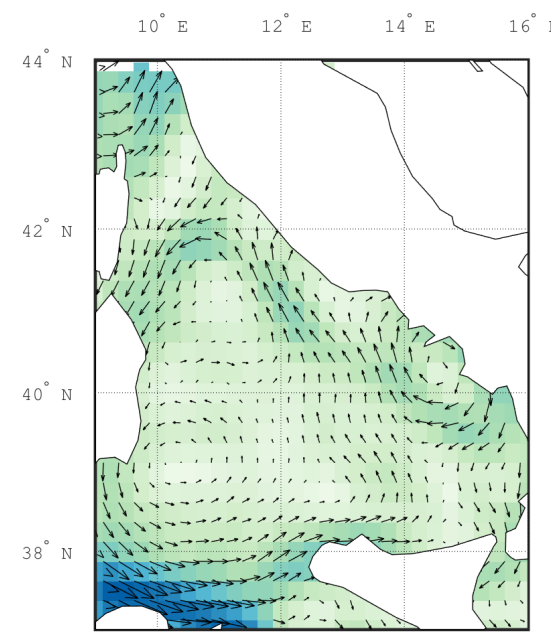

WINTER(Dec-Feb)

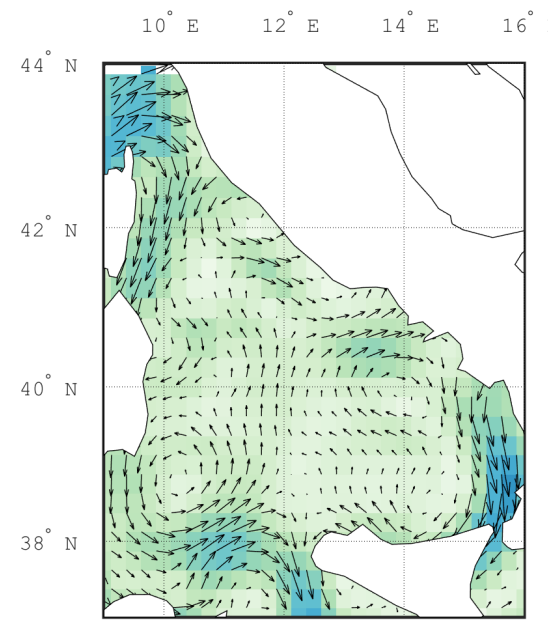

SUMMER(Jun-Aug)

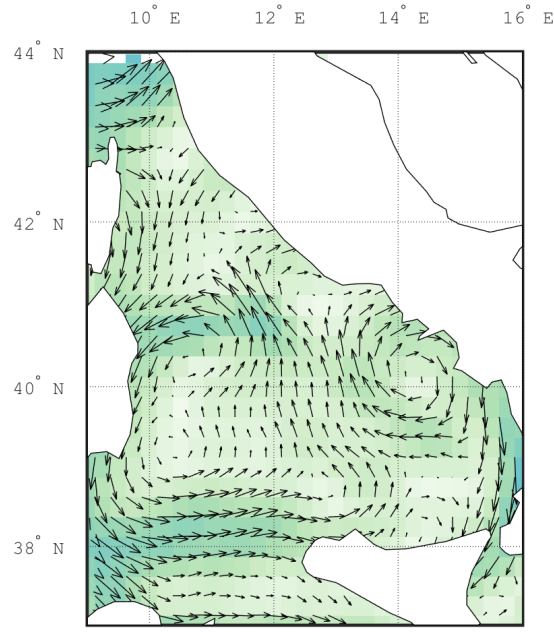

SPRING(Mar-May)

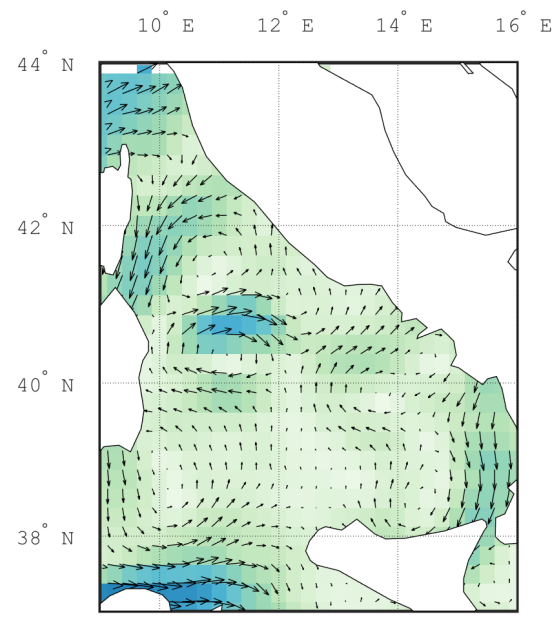

AUTUMN(Sep-Nov)

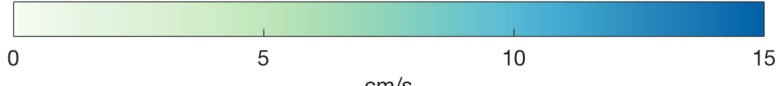

Fig. 6 1993-2014 Seasonal Mean Tyrrhenean Surface Geostrophic Currents as estimated from satellite gravity and altimetry data. Season (and corresponding months) is indicated at the left bottom of each panel. 


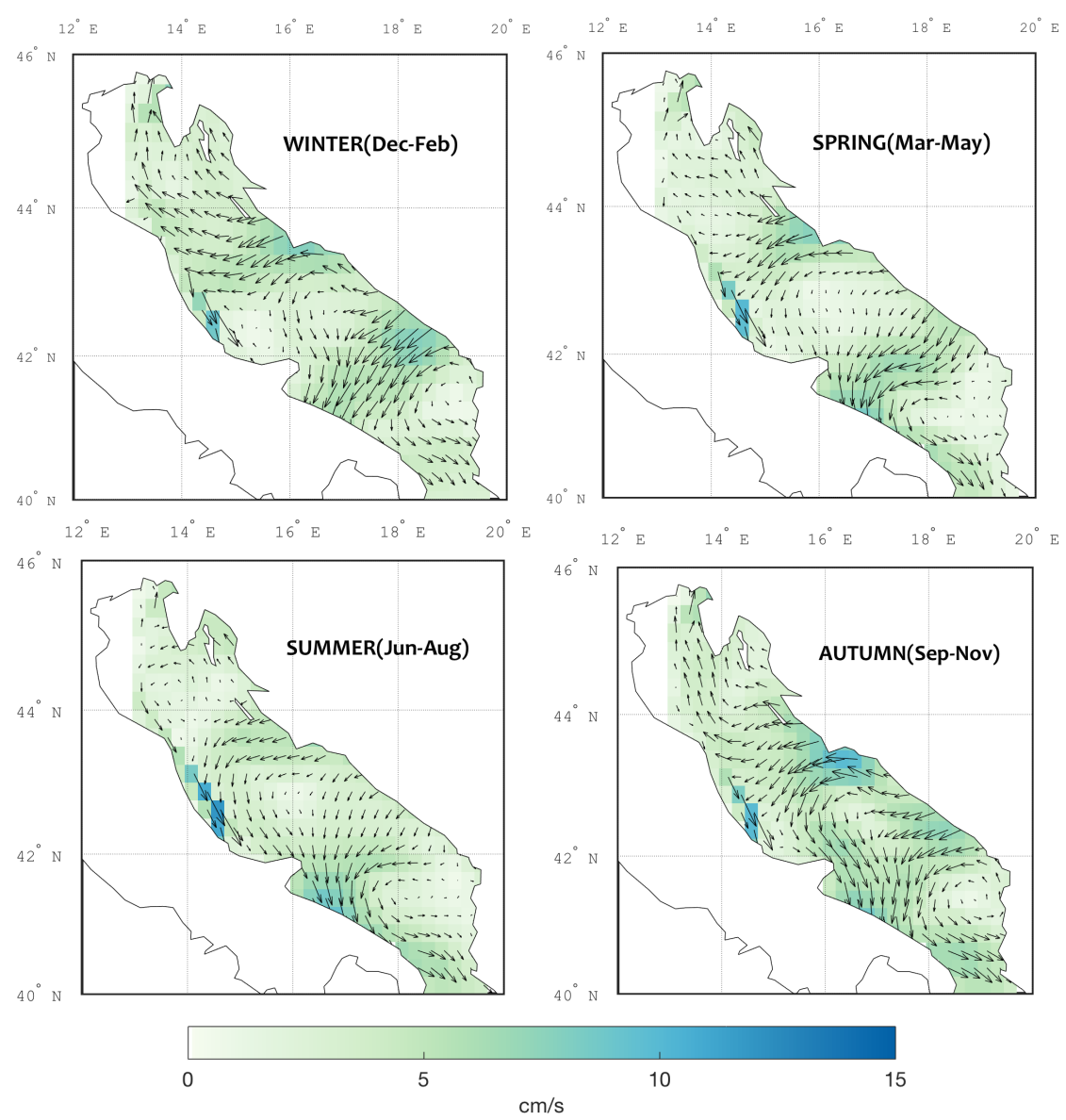

Fig. 7 1993-2014 Seasonal Mean Adriatic Surface Geostrophic Currents as estimated from satellite gravity and altimetry data by seasons. Season (and corresponding months) is indicated at the right top of each panel. 


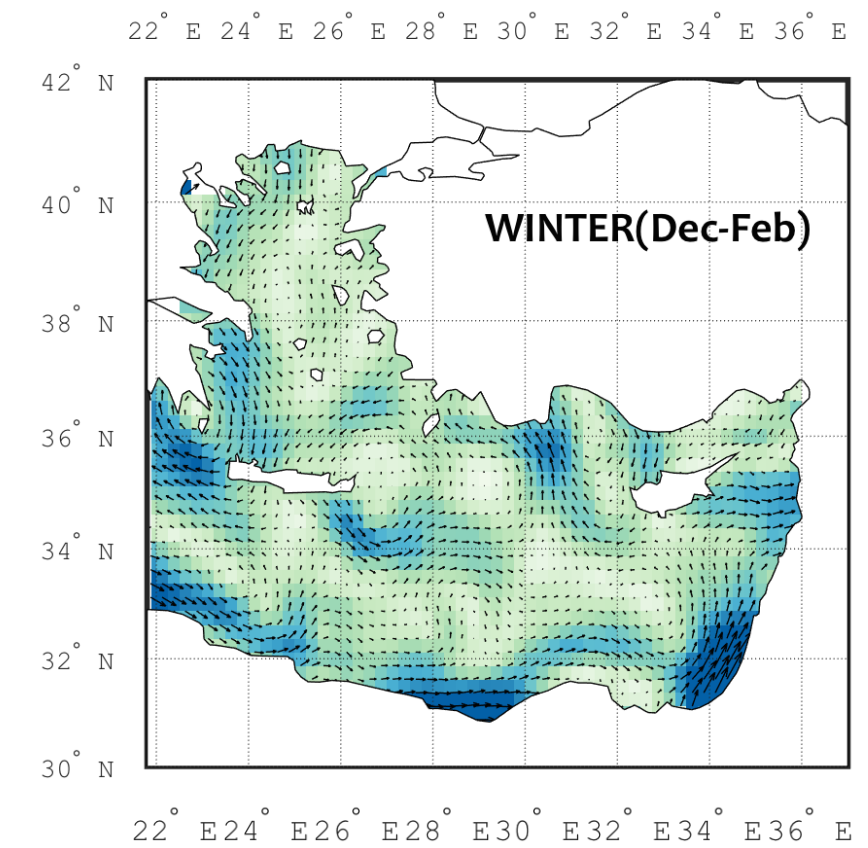

$22^{\circ} \mathrm{E} 24^{\circ} \mathrm{E} 26^{\circ} \mathrm{E} 28^{\circ} \mathrm{E} 30^{\circ} \mathrm{E} 32^{\circ} \mathrm{E} 34^{\circ} \mathrm{E} 36^{\circ} \mathrm{E}$

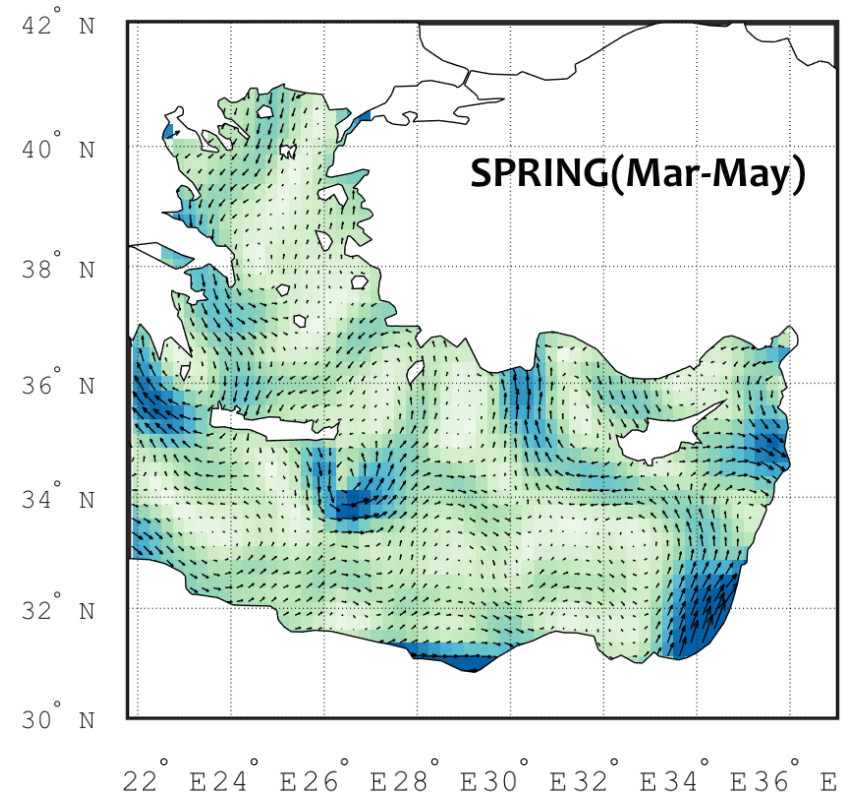

$42^{\circ} \mathrm{N}$
$40^{\circ} \mathrm{N}$
$38^{\circ} \mathrm{N}$
$36^{\circ} \mathrm{N}$
$34^{\circ} \mathrm{N}$
$32^{\circ} \mathrm{N}$
$30^{\circ} \mathrm{N}$

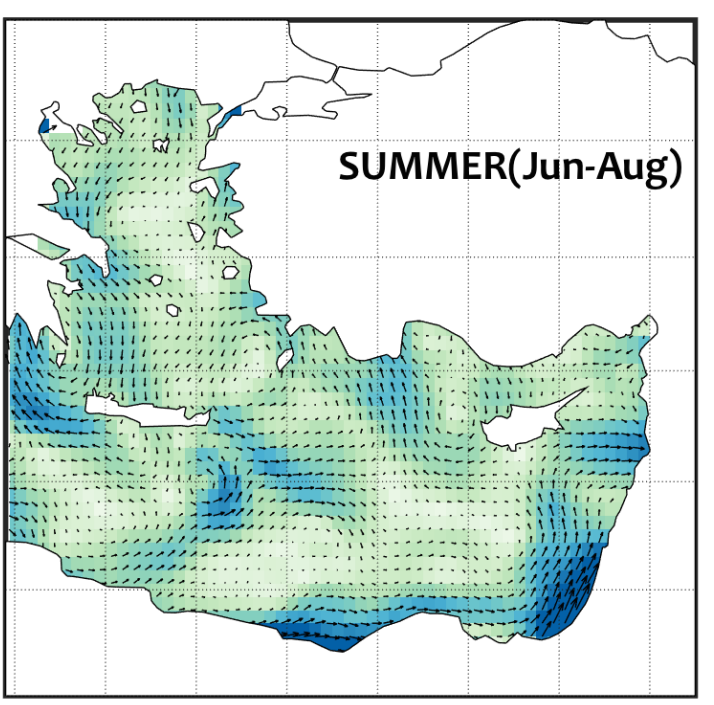

$42^{\circ} \mathrm{N}$
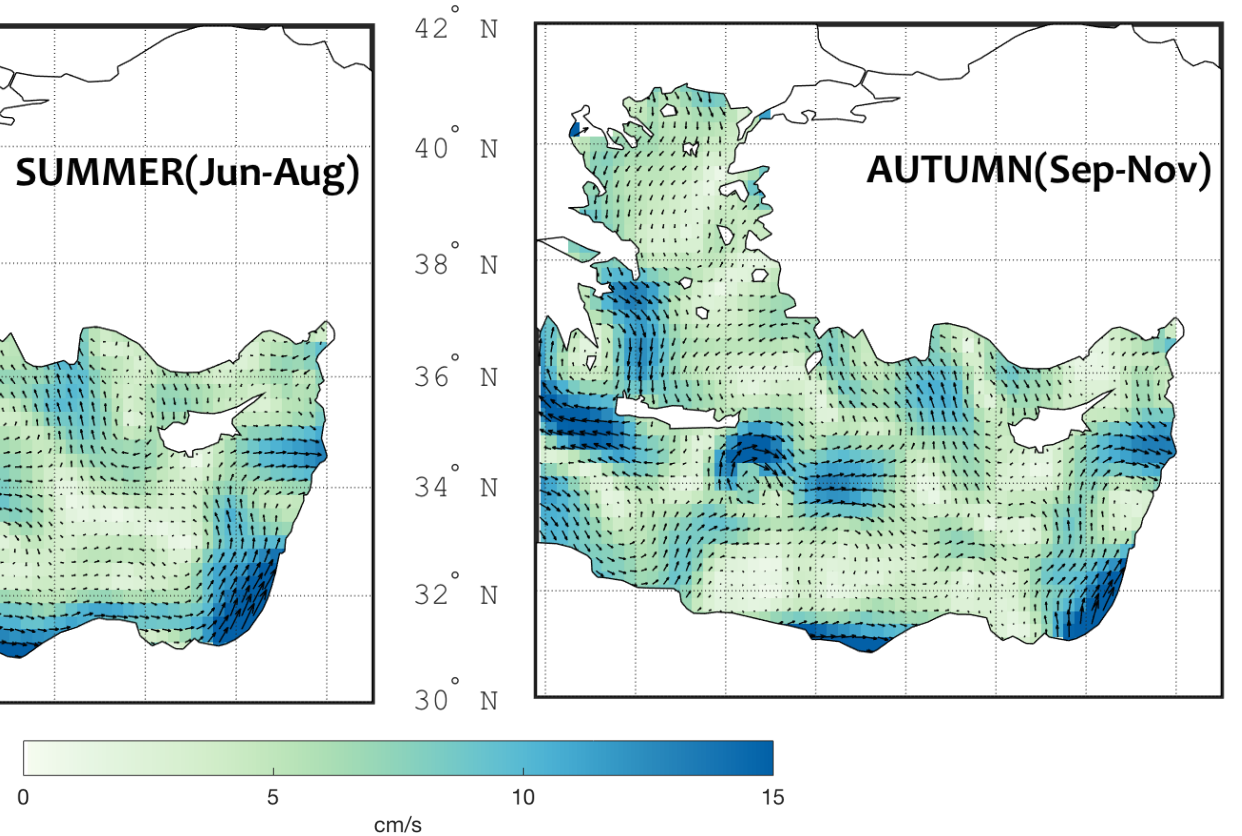

Fig. 8 1993-2014 Seasonal Mean Eastern Mediterranean Surface Geostrophic Currents as estimated from satellite gravity and altimetry. Season (and corresponding months) is indicated at the right bottom of each panel. The color scale is designed to better visualize the full range of values and its saturated to $15 \mathrm{~cm} / \mathrm{s}$, though speed at AG reaches $30 \mathrm{~cm} / \mathrm{s}$. 


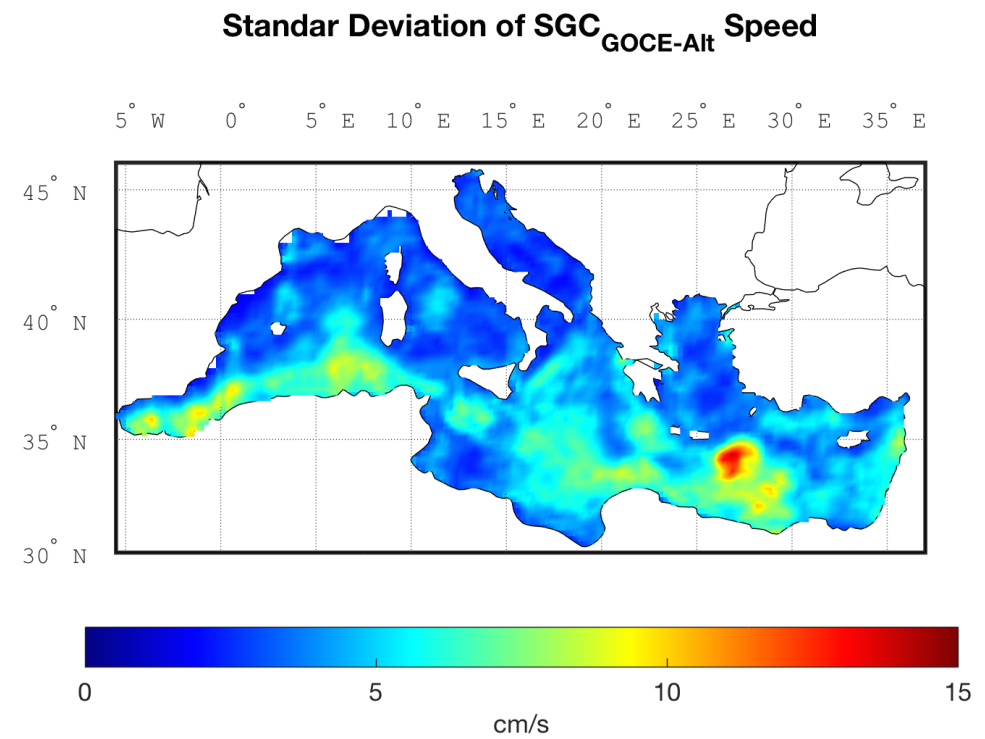

Fig. 9 Standard deviation of the Mediterranean Surface Geostrophic Currents speed as estimated from satellite gravity and altimetry data for the period 1993-2014. The color scale is designed to resolve regional features rather than extreme values and saturates at $15 \mathrm{~cm} / \mathrm{s}$.

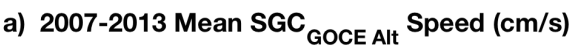
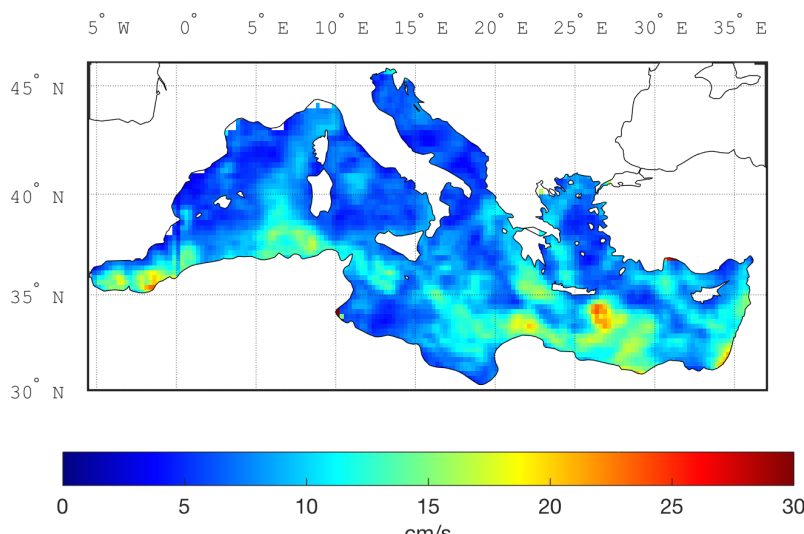

b) 2007-2013 Mean SGC Mercator $_{\text {Speed }}$
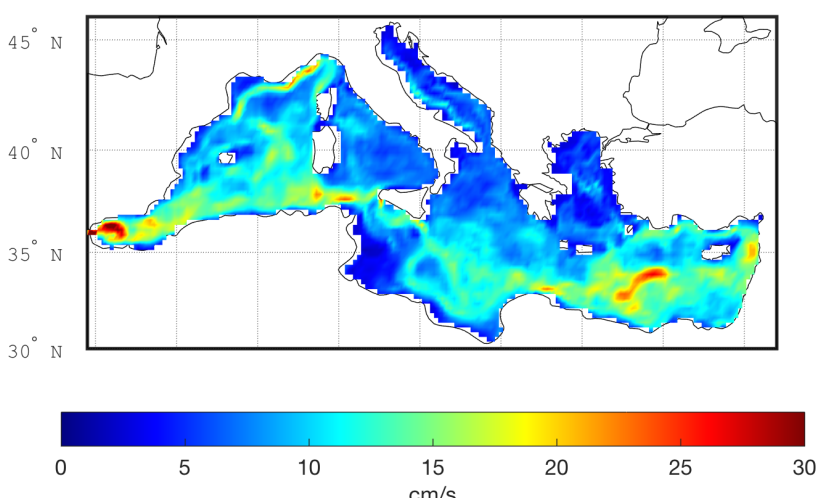

Fig. 10 Mean speed of the Mediterranean Surface Geostrophic Currents for the period 2007-2013 as estimated from: (a) satellite gravity and altimetry data, and (b) ocean model Mercator simulated data. Correlation between the two maps is 0.46 . 
a) Correlation Coeficients

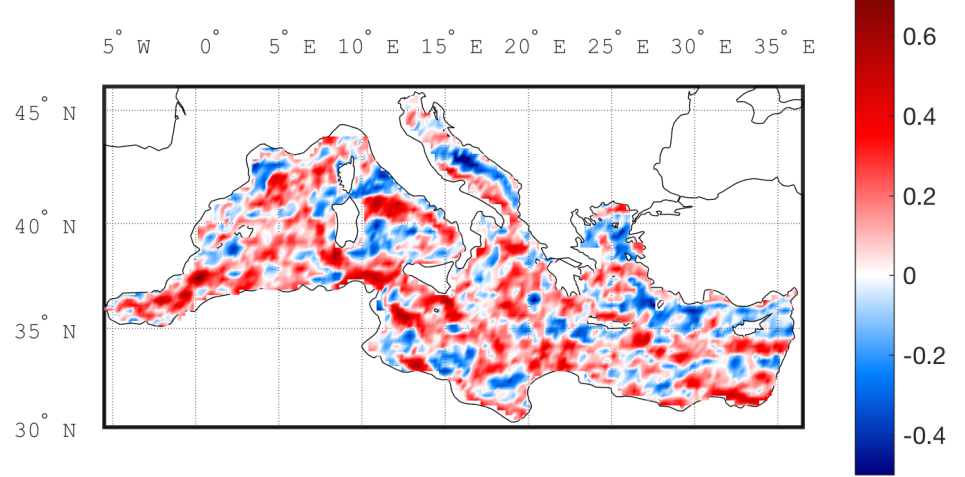

b) Veering Angle

c) Complex Correlation Coeficients

$5^{\circ} \mathrm{W} \quad 0^{\circ} \quad 5^{\circ} \mathrm{E} \quad 10^{\circ} \mathrm{E} \quad 15^{\circ} \mathrm{E} \quad 20^{\circ} \mathrm{E} \quad 25^{\circ} \mathrm{E} \quad 30^{\circ} \mathrm{E} \quad 35^{\circ} \mathrm{E}$

$5^{\circ} \mathrm{W} \quad 0^{\circ} \quad 5^{\circ} \mathrm{E} \quad 10^{\circ} \mathrm{E} \quad 15^{\circ} \mathrm{E} \quad 20^{\circ} \mathrm{E} \quad 25^{\circ} \mathrm{E} \quad 30^{\circ} \mathrm{E} \quad 35^{\circ} \mathrm{E}$


$-150$

$-50$

0

100

150

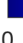

0.1

Fig. 11 Correlation between the Mediterranean Surface Geostrophic Currents Speed as estimated from satellite data (gravity and altimetry) and from ocean model Mercator simulated data (time period 2007-2013): a) correlation coefficients map; b) veering angle map; c) complex correlation coefficients map. 
a) Annual Amplitude of SGC ${ }_{\text {GOCE-Alt }}$ Speed

b) Annual Amplitude of SGC $_{\text {Mercator }}$ Speed
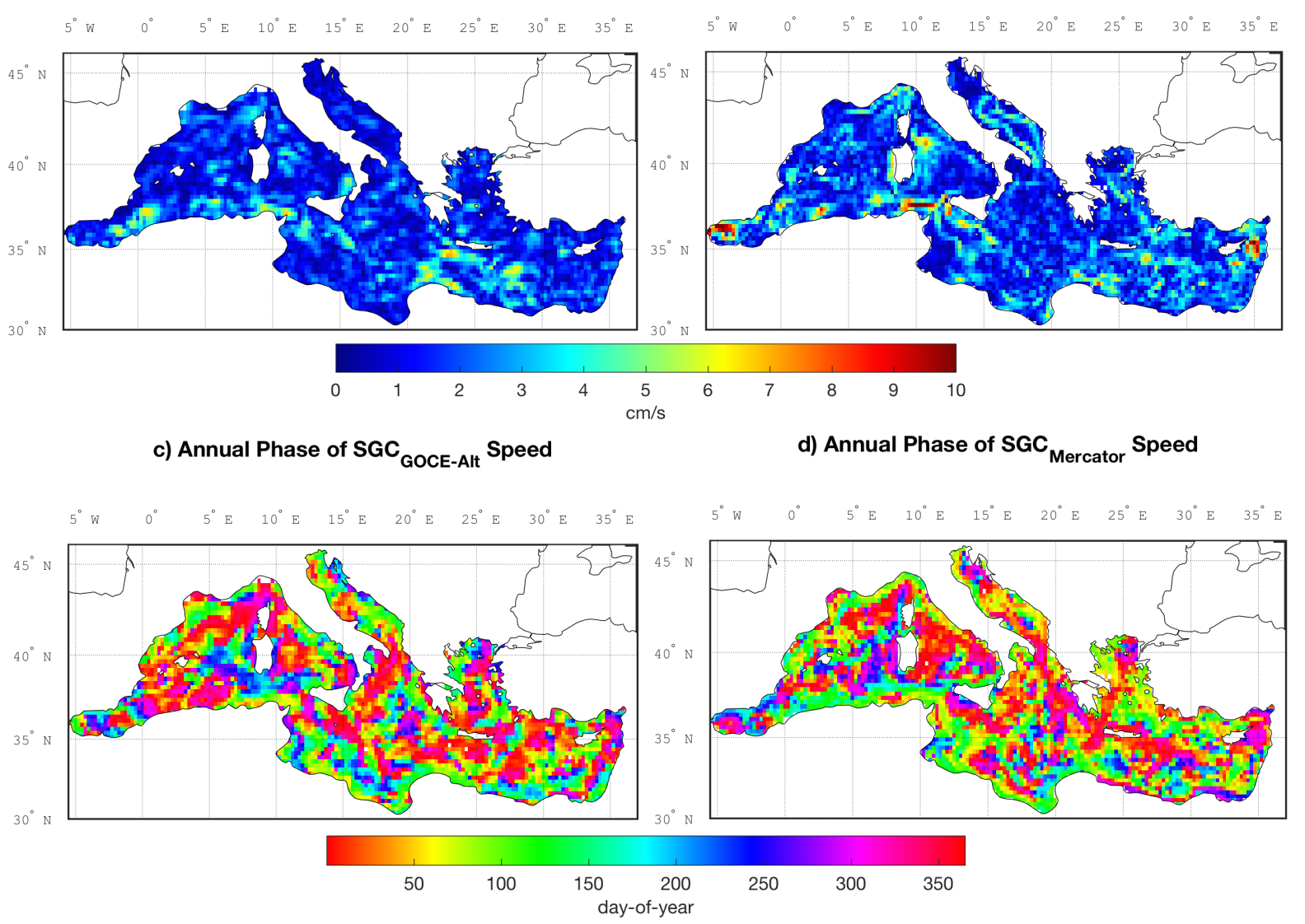

Fig. 12 Amplitude and Phase of the annual cycle of the Mediterranean Surface Geostrophic Currents for the period 2007-2013 as estimated from satellite gravity and altimetry data (left panels), and ocean model Mercator simulated data (right panels). 